\title{
El hispanismo francés y la Historia Moderna de la Monar- quía Hispánica
}

\section{French Hispanism and the Modern History of the Hispanic Monarchy}

\author{
Bernard VINCENT \\ École des Hautes Etudes en Sciences Sociales - EHESS, Paris \\ bernard.vincent@ehess.fr
}

Fecha de recepción: 30-12-2019

Fecha de aceptación: 28-01-2020

\section{RESUMEN}

La aportación del hispanismo francés a la historia moderna no ha dejado de ser importante durante las dos últimas décadas. Gracias a su buena implantación en todo el tejido académico francés, ha tenido una producción abundante de monografías y libros colectivos que abarcan todas las ramas de la historia. Sin embargo, se caracteriza por dos rasgos esenciales: el interés muy marcado por la historia política y sociopolítica, y su ambición por explicar la complejidad de la construcción de la Monarquía hispánica en el conjunto de sus territorios.

Palabras clave: Monarquía hispánica, Historiografía, Hispanismo

Topónimos: Francia

Periodo: Edad Moderna

\section{ABSTRACT}

French Hispanism has made a significant contribution to modern history throughout the last two decades. Its consolidated position within the French academic fabric has resulted in a copious production of monographs and collective books encompassing every branch of history. But it is characterized above all by two main features: a considerable interest in political and socio-political history, and the quest to explain the complexity of the construction of the Hispanic Monarchy throughout its territories.

Key words: Hispanic Monarchy, Historiography, Hispanism

Place names: France

Period: Modern Age 


\section{INTRODUCCIÓN}

Aparentemente el hispanismo francés que se dedica al estudio de la historia moderna del mundo hispánico goza de buena salud. He contabilizado más de un centenar de investigadores que están en activo trabajando en centros universitarios y a ellos se pueden sumar otros que enseñan en institutos o que siendo jubilados continúan publicando. Hace veinticinco años escribí que el hispanismo historiador francés era probablemente el más denso del mundo. Un cuarto de siglo después creo poder repetir esta afirmación.

Esta situación se debe a dos factores. Primero, la imagen de España, y más en particular, de la lengua española, que ha cambiado en la sociedad francesa a lo largo del último medio siglo. El español es claramente el idioma más estudiado como segundo idioma - después del inglés- por los alumnos de colegios e institutos. Una de las evidentes consecuencias de este hecho es la necesidad de la formación de muchos profesores en las distintas universidades. En 56 universidades francesas se enseña la lengua española, en su inmensa mayoría en departamentos de lengua, literatura y civilización española. En el seno de estos departamentos una parte de los profesores dedican sus trabajos de investigación a la civilización, es decir, casi siempre son historiadores. El otro factor es la vieja tradición de la disciplina histórica francesa de interesarse por el pasado de todas las sociedades que pueblan el mundo. Entre los alumnos de departamentos de historia varios, generación tras generación, han sido atraídos por el estudio de la historia de los espacios de habla española. Cualquiera que fuera su originaria formación, los jóvenes historiadores hispanistas se han beneficiado del magisterio de excelentes maestros: Marcel Bataillon, Noël Salomon, o Carlos Serrano de un lado; Pierre Vilar, Fernand Braudel, Pierre Chaunu o Bartolomé Bennassar del otro. Y muchos de ellos han aprovechado excepcionales condiciones de trabajo durante estancias realizadas en cualquier lugar de la Península Ibérica bajo la tutela de la Casa de Velázquez.

Esta constante atención a la historia del mundo hispánico, preferentemente moderno a causa de su compleja riqueza y de la influencia de los numerosos maestros modernistas, ha sido objeto de diversos exámenes historiográficos, desde la aportación de Joseph Perez en la revista Arbor en 1979 hasta los textos reunidos por Francisco García González a partir de un encuentro celebrado en Albacete-Chinchilla en 2006 y publicados en un volumen que data de 2009, o el original y sugestivo libro también de 2009 sobre el hispanismo francés de raíz española en el siglo XX coordinado por Ricardo García-Cárcel y Eliseo Serrano Martín. Sin olvidar los trabajos generales sobre el hispanismo francés de Antonio Niño Rodríguez, el último publicado en $2017^{1}$.

\section{EL HISPANISMO AMERICANISTA FRANCÉS Y EL INTERÉS POR OTROS CON- TINENTES \\ Una de las características comunes a todos los trabajos que acabo de citar consiste en el vocabulario empleado, acercando hispanismo a España o hispanismo a español. En estas páginas intentaré sustituir hispánico por español. De hecho, ya en el volumen editado por Francisco García González podemos leer la contribución de Michel Bertrand titulado}

1 J. Perez, "La aportación del hispanismo francés a la historia de España", en Arbor, tomo CII, 400, abril (1979); F. García González (ed.), La historia moderna de España y el hispanismo francés, Madrid, Marcial Pons, 2009; R. García Cárcel y E. Serrano Martín (eds.), Exilio, memoria personal y memoria histórica. El hispanismo francés de raíz española en el siglo XX, Zaragoza, Institución Fernando el Católico, 2009; A. Niño, Cultura y Diplomacia: Los hispanistas franceses y España, 1875-1931, Madrid, CSIC-Casa de Velázquez-SHF, 1988, y del mismo autor, Un siglo de Hispanismo en la Sorbona, París, Editions Hispaniques, 2017. 
España en América: el hispanismo francés y la conformación de un mundo colonial². Las tierras americanas de la monarquía hispánica no estaban pues olvidadas pero la expresión "España en América" era todavía significativa del acento generalmente puesto en la problemática centro-periferias, estas últimas dominadas fuertemente por el centro en el seno de una monarquía compuesta. No sé qué vocabulario emplearía Michel Bertrand diez o quince años después. Sin embargo, constato que el título de su muy reciente síntesis L'Amérique ibérique sugiere que el continente descubierto por los europeos en 1492 está en una situación más reactiva frente a la metrópoli. Además, el autor está muy atento a desarrollar un estudio que reúne territorios controlados por Portugal y territorios controlados por España. Estas reflexiones son muy representativas del camino seguido por el hispanismo modernista francés. Los horizontes han sido gradualmente ampliados. De una exclusiva atención a los territorios de la Península Ibérica (y con una marcada frontera entre España y Portugal) se ha pasado a la toma en consideración de todos los territorios europeos, africanos, americanos y asiáticos. No pretendo que esta evolución sea peculiar del hispanismo francés porque la investigación española hace el mismo recorrido —como lo muestra por ejemplo la calidad y la cantidad de trabajos sobre territorios europeos exteriores a España- pero su participación en la tendencia general es importante. Daré dos testimonios elocuentes de ello. En el manual destinado a los estudiantes para preparar las oposiciones a la enseñanza secundaria, seis profesores han escrito en 2014 un texto ambicioso y denso titulado La péninsule ibérique et le monde (1470-1650). En su introducción afirman que su objetivo es invitar a reflexionar sobre la articulación entre los distintos territorios de la Península Ibérica y un mundo en plena expansión, una pregunta que no se limita al problema de las implicaciones de la presencia y de la dominación ibéricas; debe a la vez, permitir el examen de las circulaciones y de las interacciones de todo tipo entre la península y el mundo: por ejemplo, de analizar las consecuencias de la dominación de amplios territorios ultramarinos sobre la sociedad castellana. No se trata de limitarse a un relato lineal e inexorable de la expansión europea sino de preguntarse acerca de sus efectos tanto en las sociedades ibéricas como no ibéricas y sus recepciones diferenciadas. En esta perspectiva la Península Ibérica no es el punto de partida, geográfico y cronológico, de procesos de dimensión mundial, sino un espacio de contactos y de intercambios, es decir, un interface entre espacio europeo y el mundo entero ${ }^{3}$.

En el libro ya aludido, Michel Bertrand persigue el mismo objetivo. En su presentación precisa las nuevas orientaciones de la historia colonial ibero-americana insistiendo en la emergencia de la historia global y conectada que conduce a interesarse por "las conexiones y circulaciones entre las orillas del océano Atlántico (y podríamos añadir de cualquier mar) y la contextualización de los hechos a escala mundial"4.

Si el propósito de Michel Bertrand se aplica al conjunto de las investigaciones americanistas, sea cual sea su procedencia y su idioma, evidentemente conoce bien la aportación del hispanismo francés posterior a su contribución al libro editado por Francisco García González. En 2009, subrayaba el dominio de la historia económica entre 1950 y 1970 a través de las importantes obras de Pierre Chaunu, Jean-Pierre Berthe, Ruggiero Romano, Frédéric Mauro y François Chevalier. Y luego, el de la antropología histórica, cuya figura principal francesa es Nathan Wachtel, que, practicando la historia regresiva desde

2 M. Bertrand, "España en América: el hispanismo francés y la conformación de un mundo colonial", en F. García González (ed.), La historia moderna de España y el hispanismo francés...op. cit, pp. 321-342.

3 La péninsule Ibérique et le monde, 1470-1650, París, Atalante, 2014, p.16, de Etienne Bourdeu, Antonio de Almeida Mendes, Guillaume Gaudin, Natividad Planas, Pascale Girard y Natalia Muchnik.

4 M. Bertrand, L'Amérique ibérique. Des découvertes aux indépendances, París, Armand Colin, 2019. 
nuestros tiempos, impone el concepto de aculturación aplicado al mundo amerindio. Terminaba indicando la existencia de una nueva etapa llamada el retorno del actor que podemos establecer en los años 1990. Y al respecto cita los trabajos de Zacarias Moutoukias sobre las redes sociales en el siglo XVIII, de Jean-Paul Zuñiga sobre la emigración a Chile en el siglo XVII y de Jacques Poloni-Simard sobre la identidad indígena ${ }^{5}$.

En L'Amérique ibérique es obviamente más preciso, insistiendo en las primeras páginas sobre la importancia de la síntesis de Carmen Bernand y Serge Gruzinski publicada en dos volúmenes en 1991 y 1993 y el ensayo de historia global realizado por el mismo Gruzinski en 2004, y a lo largo de las páginas utiliza numerosos libros y artículos, entre ellos muchos de investigadores franceses. El panorama es amplio, y aunque no puedo citar a todos los autores, destaca una preocupación generalizada por una historia política y social renovada. Las figuras y las trayectorias de los conquistadores han apasionado a Bernard Grunberg y más particularmente Cortés a Bartolomé Bennassar y Francisco Pizarro a Bernard Lavallé. La emigración al continente ha sido estudiada por Jean-Paul Zuñiga, pero también por Grégoire Salinero que examina las consecuencias humanas y materiales para la ciudad de Trujillo, y por Alain Hugon que hace lo que Pierre Chaunu llamaba "une pensée globale" del fenómeno.

¿Cómo gobernar las Indias? Esta es una de las más ambiciosas preguntas formuladas por el hispanismo americanista francés. Esta preocupación por una historia política y social atenta a los lazos entre historia y derecho, que debe mucho a François-Xavier Guerra tempranamente desaparecido, ha conducido a Michel Bertrand al examen de los oficiales de hacienda en Nueva-España. Más recientemente, Guillaume Gaudin analizó el universo socioprofesional y las prácticas administrativas de un oficial del Consejo de Indias entre los años 20 y 60 del siglo XVII. El uso de la corrupción tan recurrente entre los agentes de la monarquía ha sido abordado por Louise Bénat-Tachot y Pierre Ragon. Todos los trabajos recientes tienden a demostrar que el recurso de la corrupción no significaba un debilitamiento del Estado sino más bien un elemento esencial de negociación dentro del juego político.

Pierre Ragon es a la vez un especialista de la historia religiosa sin la cual las expansiones hispánica y portuguesa no se podrían entender. Este autor publicó en 2003 un libro sobre las devociones a la Virgen y a los santos y sobre las imágenes de estas devociones en la Nueva España de los siglos XVI y XVII, donde enseña el marcado enraizamiento del cristianismo americano en la reforma tridentina. En el mismo año 2003, Juan Carlos Estenssoro publicó un volumen donde analiza los distintos elementos de las catequesis (ceremonias, sermones e imágenes) dirigidos a los indios, a los africanos del Perú y a los esfuerzos de los misioneros en cuanto al trabajo de traducción en lenguas autóctonas. Aliocha Maldavsky hace a su vez un estudio minucioso de las misiones jesuíticas peruanas. Enseñando que la misión es objeto de permanentes negociaciones -por ejemplo en los decisivos aspectos lingüísticos- establece una precisa cronología entre 1568 y 1640 de los tipos de misiones. A este conjunto debemos añadir el libro de Charlotte de CastelnauL'Estoile titulado Les ouvriers d'une vigne stérile, publicado en 2000 donde se examina la labor misional de los miembros de la Compañía de Jesús en Brasil y, así mismo, la cuestión central de la práctica de las lenguas.

Otros muchos investigadores han desarrollado estudios de historia social escudriñando el trabajo y las condiciones de vida de los esclavos, como lo han hecho Jean-Pierre Tar-

5 Diversos trabajos de todos estos autores figuran en la bibliografía del libro de F. García González (ed.), La historia moderna de España y el hispanismo francés....op. cit., pp. 343-396. Falta solamente la referencia a los textos de J. P. Berthe, Estudios de la Nueva-España. De Sevilla a Manila, México, Universidad de Guadalajara / CEMCA, 1994. 
dieu para el Perú, el Ecuador y más recientemente Montevideo, o Charlotte de CastelnauL'Estoile en el Brasil del XVII a partir del relato de una esclava que había nacido en Angola. También de los indios viviendo en la frontera de Nueva Vizcaya o en la zona andina de Tucumán, objeto de las pesquisas de Christophe Giudicelli. O de los habitantes del Valle de Toluca, por los cuales se ha interesado minuciosamente Nadine Béligand. O de las sociedades mineras de Nueva-España y, más concretamente, de Zacatecas. Mientras Frédérique Langue dedicaba su atención a la aristocracia minera, Soizic Croguennec cuestionó la inestable identidad de los operariosmestizos.

El mundo urbano ha atraído a varios historiadores. Claudia Damasceno Fonseca estudió la red de ciudades del Minas Gerais brasileño en el siglo XVIII con un interés muy marcado por las relaciones entre espacio y poder, y Laurent Vidal ha publicado, entre otros trabajos, un libro sobre el caso singular del traslado en 1769 de la población de la ciudad marroquí —que pertenecía desde el siglo XVI a Portugal—al Amazonas. Arnaud Exbalin ha examinado el gobierno de la ciudad de México en el siglo XVIII lo que le permitió desvelar muchos aspectos de la vida cotidiana y de su control por la policía.

La transición del Antiguo Régimen hispánico a las independencias ha constituido otro eje de la investigación francesa. El tema principal de Annick Lempérière ha sido el de la construcción de los Estados, sobre todo en México. Clément Thibaud estudia el desarrollo del republicanismo a partir de 1750 y sus relaciones con la ciudadanía, la raza y la religión en el ámbito colombiano y venezolano. Dominique Goncalves realizó un análisis de la experiencia inversa para Cuba, donde demuestra que el mantenimiento de la isla en la órbita colonial se debe a las relaciones entre élites aristocráticas de la Habana y monarquía española.

A pesar de la rapidez del recorrido espero haber reflejado la riqueza del hispanismo americanista francés pero quiero ahora insistir sobre una idea fundamental aunque simple. El valor del conjunto de los trabajos ya citados no se puede realmente medir sin la toma en consideración de otros dedicados a espacios pertenecientes a la Monarquía Hispánica (o cercanos a ellos) pero dispersados a través de océanos y de los continentes asiático y africano. Podemos recordar que en L'aigle et le dragon, Serge Gruzinski fundaba su reflexión sobre el examen de dos acontecimientos del año 1521 que en apariencia tenían poco en común: la conquista de México por Cortés y la embajada del portugués Tomé Pires en China. El autor está atento a las interacciones a larga distancia según el canon de las historias interconectadas, lo que le conduce a preocuparse por la presencia de los sujetos de las monarquías hispánica y lusa en los cuatro continentes. Pero no es el único y son varios los modernistas hispanistas franceses que han contribuido a entender mejor las razones de esta presencia.

Junto a la multiplicación de los estudios atlánticos existen también otros estudios sobre el Océano Pacífico, empezando por el libro reciente de Bernard Lavallé. Y sabemos que las Filipinas han constituido a la vez una importante frontera y una base para llegar a los centros neurálgicos de Asia, como lo demuestra Clotilde Jacquelard en una síntesis que cubre todo el siglo XVI. Unos años antes, Pascale Girard había estudiado a partir de las crónicas escritas por los religiosos en los siglos XVI y XVII y de las obras de la evangelización redactadas en chino, la cultura misionera común a todas las órdenes religiosas. Hugues Didier ha publicado textos de gran importancia como el relato del viaje del jesuita Bento de Gois desde la India hasta China donde murió en 1607. Y por su parte, Charles Amiel y Anne Lima han dado a conocer la relación de la inquisición de Goa escrita por el francés Charles Dellion en 1687. Por último, Louise Bénat-Tachot ha cuestionado el sitio de Asia en la historiografía.

La atención al continente africano tiene dos vertientes. De un lado, el interés por los presidios norte-africanos de las monarquías ibéricas que ha sido objeto de una enorme 
producción francesa durante la época colonial (1830-1962), ha conocido recientemente un nuevo impulso lejos de su acercamiento tradicional. Mientras Maria Ghazali se interesaba por Trípoli y la Goleta en el siglo XVI, Orán es el marco de los estudios de Luis Fe Canto revelando para el siglo XVIII los entresijos de la sociedad local, desde los soldados hasta los mercaderes y los conflictos entre administración borbónica y élites locales, o de JeanFrédéric Schaub, autor de un libro sobre los judíos de la ciudad hasta su expulsión en 1669, y aún de la tesis muy reciente de Antoine Sénéchal quien, a partir de reflexiones sobre lo que era la frontera, revisita la política de la monarquía en el último tercio del siglo XVII. No hay que olvidar que Natividad Planas ha cuestionado así mismo sin cesar la realidad y los usos de la frontera entre cristiandad e islam en el mundo mediterráneo, entre preferentemente las islas Baleares y el Norte de África. De otro lado, la presencia portuguesa en la zona subsahariana y la importancia de la trata de esclavos ha llevado a Catarina Madeira Santos a preguntarse por las definiciones dadas a la esclavitud en distintos idiomas africanos y también sobre las Luces en la Angola del siglo XVIII; y a Antonio de Almeida Mendes a investigar sobre la esclavitud en las islas del Cabo Verde y en el Senegal.

\section{ESPAÑA, LAS ESPAÑAS Y EUROPA}

Si hasta aquí he insistido sobre la aportación al estudio de las posesiones ibéricas extra-europeas es para subrayar la importancia de cada una tanto en la gobernación de esta monarquía policéntrica como en las relaciones entre los diversos territorios o en las representaciones de los unos y de los otros. Pero, evidentemente, no quiero decir que el mundo europeo haya sido abandonado. Existen algunos trabajos, no muchos pero sí significativos, sobre tierras italianas o flamencas y portuguesas (en el periodo de unión de las Coronas). Un libro de Mireille Peytavin expone a través del examen de las visitas generales la inmensa complejidad de las relaciones entre la Monarquía Hispánica y las instituciones locales y regionales, principalmente las del reino de Nápoles, pero sin olvidar las del reino de Sicilia y del ducado de Milán. Alain Hugon reinterpreta el movimiento revolucionario del reino de Nápoles en 1647-1648 sobre la base de las prácticas y de los símbolos movilizados por sus actores en el mundo rural como en la capital del reino. Yves Junot se dedica al estudio de la sociedad de las ciudades de los Países Bajos españoles, sobre todo de las relaciones entre élites urbanas y monarquía, y las de los exiliados y las redes que les acogen. Jean-Frédéric Schaub ha analizado los conflictos existentes entre jurisdicciones en Portugal durante el tiempo de Olivares (1621-1640) demostrando cómo el enfrentamiento jurisdiccional es un elemento clave del ejercicio de la política. Las Españas siguen siendo un polo de atracción que suscita una multitud de acercamientos. Podemos clasificar los estudios entre unos registros clásicos (estudios económicos y socioeconómicos, minorías, estudios religiosos, políticos y sociopolíticos, culturales) a pesar de su arbitrariedad porque hay muchos puentes entre ellos en la práctica. El primero es el de una historia económica y social que, sin olvidar las técnicas y los postulados de los estudios de los años 1960-1980, se esfuerza por utilizar bases de datos y por reconstruir las redes que reúnen los, a veces, innumerables personajes estudiados. En este marco son los mercaderes los principales "héroes" de esta corriente, mercaderes de Sevilla en la transición del siglo XV al siglo XVI examinados por Béatrice Perez, mercaderes de Bilbao en el siglo XVI cuyas trayectorias están analizadas por Jean-Philippe Priotti, o mercaderes franceses de Cádiz en la transición del siglo XVIII al XIX (1778-1828), objeto de la investigación de Arnaud Bartolomei. Las problemáticas no son, por supuesto, las mismas: en Sevilla los mercaderes constituyen una sociedad frágil; en Bilbao los hombres de negocios conocen un periodo muy favorable, al contrario que los gaditanos que hacen frente a una severa crisis política y económica. Entre los trabajos de historia económica -hoy tan poco frecuentada- los de Anne Dubet tienen un lugar 
muy especial. En un primer tiempo la autora reveló la importancia de un texto del arbitrista Luis Valle de la Cerda, publicado en 1600, donde se propone reformar el crédito público y privado con la creación de erarios públicos. Luego Anne Dubet desarrolló investigaciones sobre la hacienda real en el siglo XVIII, del funcionamiento en las tres primeras décadas hasta una reflexión global sobre la centuria realizada con Sergio Solbes Ferri. Por su parte Olivier Caporossi ha abierto una investigación sobre las falsas acuñaciones de monedas.

Los mercaderes de Sevilla, que constituyen esta sociedad inquieta de la cual nos habla Béatrice Perez, son a menudo conversos. A estos últimos la autora ha dedicado un primer libro donde analiza la introducción y la actuación de la inquisición sobre esta minoría. Otros investigadores han publicado también recientemente trabajos importantes sobre el estudio de las minorías (conversos, moriscos y protestantes), desde Raphaël Carrasco y Anita Gónzalez que enriquecen su obra, hasta Rica Amran, impulsora de la excelente revista e-humanista/conversos. Mientras Michel Boeglin tomaba a Sevilla como atalaya, Vincent Parello elegía Toledo como observatorio privilegiado y Enric Porqueres enseñaba cómo en el caso de los chuetas mallorquines la alianza matrimonial definía al minoritario. Después de haber examinado la singular trayectoria de Juan de Prado, un médico converso en la primera mitad del siglo XVII, Natalia Muchnik sondea las diásporas europeas acercando los casos converso y morisco a los de los protestantes franceses y católicos ingleses. Youssef El Alaoui compara los métodos de evangelización que los jesuitas aplican a los moriscos y a los indios del Perú. Isabelle Poutrin ofrece reflexiones renovadoras acerca de la política aplicada a los moriscos a partir de los postulados jurídicos y teológicos.

De esta manera Isabelle Poutrin continúa su obra sobre la historia religiosa moderna, campo que conoce un muy notable revival en el hispanismo francés. A las aportaciones ya clásicas de Isabelle Poutrin, Françoise Crémoux y Estelle Ruiz Gálvez, se suman las de Marie- Lucie Copete sobre visiones y congregaciones, de Agueda García Garrido sobre la predicación o la vida en los conventos femininos, de Alicia Ö̈ffer-Bomsel sobre las normas del matrimonio católico, de Louis Cardaillac sobre la devoción a Santiago, de Fabrice Quero sobre la espiritualidad de la España tridentina a partir de la figura del arzobispo de Toledo Juan Martínez Siliceo, de Cécile Vincent-Cassy sobre la devoción a la santas mártires, de Antoine Roullet que ofrece unas surgentes reflexiones sobre la penitencia en los conventos de carmelitas y más particularmente el tratamiento reservado a estos fines al cuerpo. Hay que citar igualmente el muy reciente libro de Laurey Braguier sobre las beatas de la Corona de Castilla.

La historia política ha sido objeto de muchas investigaciones con dos modalidades preferentes que podemos resumir en dos preguntas: ¿Cómo gobernar un conjunto tan complejo? ¿Cuáles han sido los agentes de la administración de los Austrias y luego de los Borbones? Son bien conocidos los trabajos de Jean-Pierre Dedieu que incansablemente desmonta el sistema de gobierno de la monarquía y prepara un diccionario institucional de la España moderna. Pero Sylvain André estudia las prácticas de gobierno a través de las juntas de gobierno en la época de Felipe II. Héloïse Hermant se ciñe a los escritos que traducen los enfrentamientos entre partidos opuestos durante la minoría de Carlos II, lo que le lleva a cuestionar la noción de opinión pública; Guillaume Hanotin y Catherine Desos analizan el personal francés asistiendo a Felipe $\mathrm{V}$ durante los primeros años de su reinado; y Philippe Castejón se pregunta por el alcance de las reformas iniciadas por José de Gálvez durante el reinado de Carlos III.

Atentos así mismo a la forma del gobierno, Pascal Gandoulphe, Martine Galland- Séguéla y Thomas Glesener han adoptado la vía de la historia sociopolítica. Tienen en común el estudio de un grupo al servicio del rey, el primero en el ámbito del reino de Valencia entre mediados del siglo XVI y el primer tercio del XVII, los dos últimos directamente al servicio del soberano en una perspectiva reformista anhelada por los Borbones. Los ingenieros mili- 
tares de Martine Galland-Séguéla tienen como misión el control de los territorios cuando los oficiales flamencos de Thomas Glesener han jugado un papel relevante de mediadores políticos en el espacio europeo. Las reflexiones acerca de los modos del gobierno han provocado también una serie de estudios cuestionando obras mayores como las de Cerdán de Tallada o de Juan de Mariana o subrayando las huellas de corrientes de pensamiento como el agustinismo abordado por Marina Mestre y Philippe Rabaté, o el tacitismo examinado por Alexandra Merle, Alice Ö̈ffer- Bomsel y Paloma Bravo.

Las investigaciones de Guillaume Hanotin están principalmente apoyadas en la acción del embajador Michel-Jean Amelot de Gournay (1705-1709). Constituyen un elemento importante de un grupo de trabajos que se dedican a la historia diplomática, a la cual Didier Ozanam ha dedicado gran parte de una obra pionera. Alain Hugon ha estudiado las relaciones hispano-francesas durante el periodo de paz de 1598 a 1635, evidenciando hasta qué punto la Monarquía Hispánica posee una gestión administrativa moderna y cómo recurre a la figura del espía mayor. Bertrand Haan ha sondeado todos los detalles que han conducido a la firma por Felipe III y Enrique II del tratado de Cateau-Cambrésis que asegura paz, justicia y amistad. El papel de los agentes generales franceses en el Madrid del siglo XVIII está estudiado por Sylvain Lloret. Y el de los arzobispos de Mayence está en el corazón del trabajo de Etienne Bourdeu, a la vez electores del emperador del Santo Imperio Romano-Germánico y archicancilleres imperiales, como impulsores de las redes favorables a la monarquía hispánica en los territorios del Santo Imperio.

El libro de Jean-Frédéric Schaub La France espagnole es un ensayo de historia política cuestionando lo que representaba el modelo hispánico en el siglo XVII, pero también se presenta como un intento de historia cultural. A este último dominio pertenecen numerosos estudios que se sitúan a la frontera entre historia, antropología y literatura, como los de Augustin Redondo, de Roger Chartier o de Michèle Guillemont para dar algunos ejemplos entre los más significativos. Pero en la producción reciente se pueden, además, citar las aportaciones de Maud le Guellec sobre la prensa del siglo XVIII, donde analiza la emergencia de un género nuevo que rompe los códigos tradicionales de la escritura, y de Claire Bouvier, quien a través de la obra del jesuita Pedro de Rivadeneira, sondea, de un lado, las relaciones entre escritor y poder y, de otro, las relaciones entre manuscritos e impresos. En cuanto a la historia del arte disponemos de varios catálogos de museos y de exposiciones establecidos por Véronique Gérard-Powell y Claudia Ressort, del libro de Cécile VincentCassy sobre las representaciones de las santas mártires, y de los estudios de Nicolás Morales sobre la comunidad de los músicos madrileños en el siglo XVIII.

A esta larga lista de trabajos, casi todos individuales, se añaden un sin fin de actas de coloquios, generalmente organizados por centros de investigaciones ubicados en universidades (Caen, Montpellier, París, etc...). Reúnen contribuciones de investigadores de varios países entre los cuales los más numerosos son, obviamente, españoles y franceses. Existen al menos dos series importantes. Una es la del Centre de Recherche sur l'Espagne des XVIe et XVIIe siècles (CRES), dirigido en Paris III durante veinte años por Augustin Redondo y después por Pierre Civil. A este centro se ha debido, en gran parte, la publicación reciente de encuentros sobre las relaciones de sucesos. La otra depende del departamento de lengua, literatura y civilización de Paris IV. Publicada en la colección Ibérica creada por Annie Molinié-Bertrand, tiene más de treinta volúmenes, el último coordinado por Béatrice Perez es un homenaje a Araceli Guillaume-Alonso, entonces directora de la colección. A estas series hay que añadir la amplísima colección de jornadas y coloquios publicados por la Casa de Velázquez ${ }^{6}$.

6 La lista de las actas de reuniones es infinita. Por falta de espacio no puedo dar aquí una lista. El lector 
Dos tipos de publicaciones deben ser aun mencionadas. Uno está constituido por libros destinados a un amplio público. Intentan generalmente ofrecer una síntesis sobre un reinado o un siglo (a menudo el Siglo de Oro) o una biografía de una personalidad relevante. Así la figura o el reinado de Carlos Quinto han sido objetos de los libros de Joseph Perez, de Pierre Chaunu y Michelle Escamilla o de Grégoire Salinero mientras Louise Bénat-Tachot y Bernard Lavallé han escrito un libro sobre la América de Carlos Quinto. Al reinado de Felipe II ha dedicado un libro Joseph Perez, y Alain Hugon otro al reinado de Felipe IV. He aludido más arriba a biografías de Cortés y Pizarro, pero existen otras sobre Cervantes, don Juan de Austria, Velázquez o Teresa de Jesús. La otra modalidad es la de obras de síntesis cuyos potenciales lectores son los candidatos a oposiciones (agrégation y capes) de enseñanza de lengua española o de historia. Estos manuales deben estar escritos en un lapso corto de tiempo pero a pesar de este apremio algunos de ellos tienen una gran calidad ${ }^{7}$.

No hay que olvidar la existencia de revistas donde los modernistas hispanistas franceses suelen expresarse. La decana es el Bulletin Hispanique, creado en Burdeos en 1899. Los Mélanges de la Casa de Velázquez aparecieron en 1965. En 2006 vio la luz la revista en línea e-Spania, cuyo campo es el de los estudios medievales y modernos. En 2017 dedicó su número al lugar ocupado por Asia en la historiografía de la monarquía católica. En 2013 la Société des Hispanistes Français fundó Hispanismes, otra revista en línea. Algunas revistas de Historia, por ejemplo, la Revue d'Histoire Moderne et Contemporaine y los Cahiers du Framespa contienen una notable presencia sobre estudios dedicados a la Monarquía Hispánica. En concreto, los Cahiers du Framespa (Toulouse) van a publicar un número sobre la obra de Bartolomé Bennassar, fallecido en noviembre de 2018.

Podemos constatar que este importante conjunto no se aparta de la tónica general de los estudios de historia moderna hispánica. Si ninguna rama de la disciplina está abandonada, domina desde al menos dos décadas la historia política y sociopolítica. Las palabras claves utilizadas son gobierno, administración, élites, redes, justicia, gracia, movilidad geográfica y social, exclusión, integración, frontera, globalización. La postergación de la historia económica, salvo notables excepciones, es preocupante. La historia rural, que ha sido tan brillante, casi ha desaparecido, siendo actualmente Francis Brumont, que yo sepa, el único representante de la escuela hispanista y ruralista francesa.

Querría terminar evocando dos libros que me han llamado la atención particularmente y que son portadores de perspectivas interesantes. El primero es el libro de Sébastien Malaprade, donde el autor reconstruye las fases del ascenso y luego del descenso en la sociedad de una familia giennense cuya figura principal fue próxima a Olivares. La investigación, sin ser exactamente un ejercicio de micro-historia, debe mucho a esta práctica que finalmente ni el hispanismo modernista francés ni el modernismo hispánico en general han practicado mucho a pesar de algunos éxitos importantes. Esta vía podría ser un eficaz remedio a la penuria de estudios de historia rural. El segundo libro se debe a la experta pluma de Thomas Calvo. Es un ensayo a la vez de historia política, de historia social y de historia cultural a partir de las autobiografías de siete soldados — siete improbables escritoresde la primera mitad del siglo XVII, empezando por el famoso Discurso y vida de Alonso de Contreras. Más allá de lo que representa el escrito es, entre las cuatro partes del mundo, toda la Monarquía Hispánica quien está desvelada. Del libro de Sébastien Malaprade al de

encontrará los títulos en los distintos programas en la web.

7 Entre los más recientes están el citado en la nota 3, coordinado por Etienne Bourdeu, y en La péninsule Ibérique et le monde (1470-1640), París, SEDES, 2013, coordinado por Guillaume Hanotin con Boris Jeanne, Soizic Croguennec, Bertrand Haan y Antoine Roulet. Los dos volúmenes tienen el mismo título que corresponden al tema propuesto en las oposiciones. 
Thomas Calvo comprobamos quetodas las escalas, de lo micro a lo macro, son provechosas para el historiador.

\section{CONCLUSIÓN}

Espero haber dado una fiel idea de lo que es hoy el hispanismo modernista francés. He insistido en la existencia de varias de sus características actuales. Por una parte, la abundancia de los trabajos de historia política y sociopolítica, y la renovación de la historia de lo religioso. Por otra, el afán de entender cómo la Monarquía Hispánica —o las monarquías ibéricas - ha(n) podido y ha(n) sabido mantenerse durante siglos a pesar de múltiples dificultades internas y externas, desde la dispersión y la heterogeneidad de los territorios hasta la competencia de las potencias rivales. De esta manera los hispanistas franceses han participado en el movimiento internacional de desarrollo y evolución de la historia moderna hispánica. Pero a su vez se han dirigido a un público francés, empezando por los alumnos de las universidades, acostumbrado a pensar a partir de un modelo de estado centralizado alejado del muy original y complejo de la monarquía hispánica. Creo que en este doble frente el balance es más que notable.

Sin embargo, las perspectivas no son especialmente esperanzadoras. No se pueden obviar las consecuencias del dominio lingüístico ejercido por el inglés. La difusión de los estudios publicados en francés -y cada uno se expresa mejor en su lengua materna- no es muy fácil. A este fenómeno, que afecta evidentemente a otros idiomas, se añaden problemas de política universitaria interna. Las letras y ciencias sociales sufren una merma de puestos de titulares y de catedráticos ofrecidos a concurso. Si la historia contemporánea (la de los siglos XX y XXI) llega a conservar más o menos sus efectivos, el "modernismo", como el medievalismo, está muy penalizado tanto en lengua española como en historia. ¿Qué porvenir podrán tener los brillantes doctores recientes? Y ¿cuáles serán los estímulos de sus sucesores? De hecho, el modernismo hispánico francés ha dado durante las últimas décadas muchos y buenos frutos. ¿Pero cuánto tiempo durará esta cosecha?

\section{BIBLIOGRAFÍA}

Almeida Mendes, A. de y Thibaud Cl., Esclavage et traite. Afrique, Europe, Amériques, Maghreb, París, Les Arènes, 2019

Amiel, Ch. y Lima, A. (eds.), L'inquisition de Goa, la relation de Charles Dellion (1687), París, Chandeigne, 1997

Bartolomei, A., Les marchands français de Cadix et la crise de la Carrera de Indias (17781824), Madrid, Casa de Velázquez, 2017

Béligand, N., Entre lagunas y volcanes. Una historia del valle de Toluca (finales del siglo XVsiglo XVIII), 2 vols., México, Colegio de Michoacán y Centro de Estudios Mexicanos y Centroamericanos, 2017-2018

Bénat-Tachot, L. y Lavallé, B., L'Amérique de Charles Quint, Bordeaux, PressesUniversitaires de Bordeaux, 2005

Bennassar, B., Cortés, le Conquérant de l'impossible, París, Payot, 2011

- Vélasquez: une vie, París, De Fallois, 2010

- Don Juan de Austria: un héroe para un imperio, Madrid, Temas de Hoy, 2000

Bernand, C. y Gruzinski, S., Histoire du Nouveau Monde, 2 vols., París, Fayard, 1991 y 1993

Berthe, J. P., Estudios de la Nueva España. De Sevilla a Manila, México, Universidad de Guadalajara / CEMCA, 1994

Bertrand, M., L'Amérique ibérique. Des découvertes aux indépendances, París, Armand Colin, 2019 
Boeglin, M., Entre la Cruz y el Corán: Ios moriscos de Sevilla (1570-1613), Sevilla, Instituto de la Cultura y de las Artes de Sevilla, 2010

Bourdeu, E., Les archevêques de Mayence et la présence espagnole dans le Saint Empire (XVle-XVIle siècles), Madrid, Casa de Velázquez, 2015

Braguier, L., Servantes de Dieu. Les beatas de la couronne de Castille (1450-1600), Rennes, Presses universitaires de Rennes, 2019

Calvo, T., Espadas y plumas en la monarquía hispana. Alonso Contreras y otras vidas de soldados (1600-1650), Madrid, El Colegio de Michoacán y la Casa de Velázquez, 2019

Canavaggio, J., Cervantès, París, Mazarine, 1986; ed. aumentada, París, Fayard, 1997

Cardaillac, L., Santiago acá, allá y acullá. Miscelánea de estudios jacobeos, Zapopán, Colegio de Jalisco, 2004

Carrasco, R., Deportados en nombre de Dios. La expulsión de los moriscos: cuarto centenario de una ignominia, Barcelona, Destino, 2009

Castelnau-L'Estoile, Ch., Les ouvriers d'une vigne stérile. Les jésuites et la conversión des indiens au Brésil, París, Fondation Calouste Gulbenkian, 2000

- Páscoa et ses deux maris. Une esclave entre Angola, Brésil et Portugal au XVIle siècle, París, PUF, 2019

Castelnau-L'Estoile, Ch., Copete M. L., Maldavsky A., Zupanov I., Missions d'évangélisation et circulation des savoirs. XVle-XVIII siècles, Madrid, Casa de Velázquez, 2011

Chartier, R., Cardenio entre Cervantès et Shakespeare. Histoire d'une pièce perdue, París, Gallimard, 2011

Chaunu, P. y Escamilla, M., Charles Quint, París, Taillandier, 2000

Civil, P., Crémoux, F. y Sanz Hermida, J. (eds.), España y el mundo mediterráneo a través de las relaciones de sucesos (1500-1750), Salamanca, Universidad de Salamanca, 2008

Crémoux, F., Las edades de lo sagrado: los milagros de Nuestra Señora de Guadalupe y sus reescrituras (siglos $X V-X V I$ ), estudio y edición crítica, Zaragoza, Institución Fernando el Católico, 2015

Croguennec, S., Société minière et monde métis. Le centre-nord de la Nouvelle-Espagne au XVIIle siècle, Madrid, Casa de Velázquez, 2016

Damasceno Fonseca ,Cl., Arraias e Vilas d'El Rei. Espaço e poder nas Minas setecentistas, Belo Horizonte, UFMG, 2011

Dedieu, J. P., Après le roi. Essai sur l'effondrement de la Monarchie espagnole, Madrid, Casa de Velázquez, 2010

Desos, C., Les Français de Philippe V. Un modèle nouveau pour gouverner l'Espagne (1700-1724), Strasbourg, Presses Universitaires de Strasbourg, 2009

Didier, H., Fantômes d'islam et de Chine. Le voyage de Bento de Gois s.j. (1603-1607), París, Chandeigne, 2003

Dubet, A., Réformer les finances espagnoles au Siècle d'Or. Le projet Valle de la Cerda, Clermont-Ferrand, Presses universitaires Blaise Pascal, 2000

- Jean Orry et la réforme du gouvernement de l'Espagne (1701-1706), Clermont-Ferrand, Presses universitaires Blaise Pascal, 2009

EIAlaoui, Y., Jésuites, Morisques et Indiens. Etude comparative des méthodes d'évangélisation de la Compagnie de Jésus d'après les traités de José de Acosta (1589) et d'Ignacio de las Casas (1605-1607), París, Champion, 2006

Escamilla, M., Le Siècle d'or de l'Espagne. Apogée et déclin, 1492-1598, París, Taillandier, 2000

Estensorro Fuchs, J. C., Del paganismo a la santidad. La incorporación de los indios del Perú al catolicismo, 1532-1750, Lima, Institut français d'études andines, 2003 
Exbalin, A., La grande tuerie des chiens. Enquête sur les canicides dans le Mexique colonial, París, Payot, 2020

Galland-Séguéla, M., Les ingénieurs militaires espagnoles de 1710 à 1803. Etude prosopographique et sociale d'un corps d'élite, Madrid, Casa de Velázquez, 2009

Gandoulphe, P., Au service du roi. Institutions de gouvernement et officiers dans le royaume de Valence (1556-1624), Montpellier, Etilal, 2005

García Cárcel, R. y Serrano Martín, E. (eds.), Exilio, memoria personal y memoria histórica. El hispanismo francés de raíz española en el siglo XX, Zaragoza, Institución Fernando el Católico, 2009

García González, F. (ed.), La historia moderna de España y el hispanismo francés, Madrid, Marcial Pons, 2009

Gaudin, G., Penser et gouverner le Nouveau Monde au XVIIe siècle. L'empire de papier de Juan Diez de la Calle, commis du Conseil des Indes, París, L'Harmattan, 2013

Gérard-Powell, V. y Ressort, Cl., Musée du Louvre. Département de peintures. Catalogue raisonné: Ecole espagnole et portugaise, París, Réunion des Musées Nationaux, 2002

Girard, P., Les religieux occidentaux en Chine à l'époque moderne, Lisboa-París, Centre culturel Calouste Gulbenkian, 2000

Giudicelli, Ch., Pour une géopolitique de la guerre des Tepehuán 1616-1619: alliances indiennes, quadrillage colonial et taxinomie ethnographique au Nord-Ouest du Mexique, París, Université de Paris III, 2003

Glesener, T., L'empire des exilés. Les Flamands et le gouvernement de l'Espagne au XVIIle siècle, Madrid, Casa de Velázquez, 2017

Goncalves, D., Le planteur et le roi. Etude des relations entre les élites aristocratiques havanaises et la Couronne espagnole. 1763-1838, Madrid, Casa de Velázquez, 2008

Gruzinski, S., Les quatre parties du monde. Histoire d'une mondialisation, París, La Martinière, 2004

- L'aigle et le dragon. Démesure européenne et mondialisation au XVIe siècle, París, Fayard, 2012

Guillemont, M., Recherches sur la violence verbale en Espagne au XVIe et XVIle siècles (aspects sociaux, culturels et littéraires), Lille, Atelier nationale des thèses, 2001

Haan, B., Une paix pour l'éternité. La négociation du traité de Cateau-Cambrésis, Madrid, Casa de Velázquez, 2010

- L'amitié entre princes. Une alliance franco-espagnole au temps des guerres de Religion (1560-1570), París, P.U.F., 2011

Hanotin, G., Ambassadeurs de deux couronnes: Amelot et les Bourbons, entre commerce et diplomatie, Madrid, Casa de Velázquez, 2018

Hanotin, G., Jeanne, B., Croguennec, S., Haan, B. y Roullet, A., La Péninsule ibérique et le monde (1470-1640), París, SEDES, 2013

Hermant, E., Guerres de plumes. Publicité et cultures politiques dans l'Espagne du XVIIe siècle, Madrid, Casa de Velázquez, 2012

Jacquelard, C., De Séville à Manille, les Espagnols en mer de Chine (1520-1610), París, Les Indes Savantes, 2015

Hugon, A., Au service du Roi Catholique: "honorables ambassadeurs" et "divins espions" face à la France: représentation diplomatique et service secret dans les relations hispanofrançaises de 1598 à 1635, Madrid, Casa de Velázquez, 2004

- Naples insurgée 1647-1648. De l'événement à la mémoire, Rennes, PUR, 2011

- Philippe IV. Le siècle de Vélasquez, París, Payot, 2014

- La Grande Migration. De l'Espagne à l'Amérique, 1492-1700, París, Vendémiaire, 2019

Langue, F., Los señores de Zacatecas. Una aristocracia minera en el siglo XVIII novohispano, 
México, Fondo de Cultura Económica, 1999

Lavallé, B., Pacifique. A la croisée des empires XVIe-XIXe siècles, París, Vendémiaire, 2018.

- Francisco Pizarro, conquistador de l'extrême, París, Payot, 2004

Le Guellec, M., Presse et culture dans l'Espagne des Lumières, Madrid, Casa de Velázquez, 2016

Lempérière, A., Entre Dieu et le roi, la république. Mexico, XVI-XIX`siècles, París, Les Belles Lettres, 2004

Malaprade, S., Des châteaux en Espagne. Gouvernement des finances et mobilité sociale au XVIIe siècle, Limoges, Presses universitaires de Limoges, 2018

Maldavsky, A., Vocaciones inciertas. Misión y misioneros en la provincia jesuita del Perú en los siglos XVI y XVII, Madrid, CSIC, 2012

Merle, A., Le miroir ottoman. Une image politique des hommes dans la littérature espagnole et française $\left(X V I^{\circ}-X V I I^{\circ}\right.$ siècles ), París, PUPS, Iberia, 2003

Merle, A. y Oïffer-Bomsel, A., Tacite et le tacitisme en Europe à l'époque moderne, París, Honoré Champion, 2017

Mestre, M., Rabaté, Ph. dir., Agustín en España (siglos XVI y XVII), aspectos de filosofía, teología y espiritualidad, Toulouse, Presses universitaires du Mirail, 2011

Morales, N., L'artiste de Cour dans l'Espagne du XVIIle siècle. Etude de la communauté des musiciens au service de Philippe V (1700-1746), Madrid, Casa de Velázquez, 2007

Muchnik, N., Une vie marrane. Les pérégrinations de Juan de Prado dans l'Europe du XVIIe siècle, París, Honoré Champion, 2005

Muchnik, N. y Monge M., L'Europe des diasporas (XVI-XVIII siècle), París, PUF, 2019

Niño, A., Cultura y Diplomacia. Los hispanistas franceses y España (1875-1931), Madrid, CSIC / Casa de Velázquez - SHF, 1988

- Un siglo de Hispanismo en la Sorbona, París, Editions Hispaniques, 2017

Ozanam, D., Les diplomates espagnols du XVIII ${ }^{\circ}$ siècle, Madrid-Bordeaux, Casa de Velázquez-Maison des Pays Ibériques, 1998

- Un español en la corte de Luis XV: cartas confidenciales del embajador Jaime Masones de Lima, 1752-1754, Alicante, Universidad de Alicante, 2001

Ozanam, D. y Téllez Alarcia, D. (eds.), Misión en París. Correspondencia particular entre el Marqués de la Ensenada y el Duque de Huescar (1746-1749), Logroño, Instituto de Estudios Riojanos, 2011

Oïffer-Bomsel, A., Etudes des aspects doctinaux du mariage catholique après le Concile de Trente et des litiges matrimoniaux en Andalousie: fiançailles, nullité du mariage et divorce (XVIe-XVIle siècles), Villeneuve d'Ascq, Presses universitaires du Septentrion, 2001

Parello, V., Les judéo-convers: Tolède, XVe-XVle siècles. De l'exclusion à l'intégration, París, L'Harmattan, 1999

Perez, B., Les marchands de Séville. Une société inquiète (XVe-XVle siècles), París, Presses de l'Université Paris-Sorbonne, Ibérica, 2003

- Inquisition, pouvoir, société. La province de Séville et ses judéoconvers sous les Rois Catholiques, París, Honoré Champion, 2007

Perez, B. (ed.), La Reputación. Quête individuelle et aspiration collective dans l'Espagne des Hasbourg. Hommage au professeur Araceli Guillaume-Alonso, París, PUPS, Ibérica, 2018

Perez, J., "La aportación del hispanismo francés en la historia de España", Arbor, tomo CII, núm. 400, abril 1979

- Charles Quint, empereur des deux mondes, París, Gallimard, 1994

— L'Espagne de Philippe II, París, Le Grand Livre du Mois, 1999 
— Thérèse d'Avila et l'Espagne, París, Fayard, 2008

Peytavin, M., Visites et gouvernement dans le royaume de Naples (XVIe-XVIIe siècles), Madrid, Casa de Velázquez, 2003

Porqueres, E., Lourde alliance. Mariage et identité chez les descendants de juifs convertis à Majorque (1435-1750), París, Kimé, 1995

Poutrin, I., Convertir les musulmans. Espagne, 1491-1609, París, P.U.F., 2012

Priotti, J. P., Bilbao et ses marchands au XVIe siècle. Genèse d'une croissance, Villeneuve d'Ascq, Presses universitaire du septentrion, 2004

Quero, F., Juan Martínez Siliceo (1486?-1557) et la spiritualité de l'Espagne pré-tridentine, París, Honoré Champion, 2014

Ragon, P., Les saints et les images au Mexique (XVe-XVIIle siècles), París, L'Harmattan, 2003

- Pouvoir et corruption aux Indes espagnoles. Le gouvernement du comte de Baños, viceroi du Mexique (1660-1664), París, Belin, 2016

Redondo, A., Revistando las culturas del Siglo de oro. Mentalidades, tradiciones culturales, creaciones paraliterarias y literarias, Salamanca, Universidad de Salamanca, 2007

Roullet, A., Corps et pénitence : les carmélites déchaussées espagnoles (ca 1560-ca 1640), Madrid, Casa de Velázquez, 2015

Ruiz Gálvez, E. (ed.), L'immaculisme : un imaginaire religieux dans sa projection sociale, París, Indigo, 2009

Salinero, G., Une ville entre deux mondes. Trujillo d'Espagne et les Indes au XVIe siècle. Pour une histoire de la mobilité à l'époque moderne, Madrid, Casa de Velázquez, 2006

- Les empires de Charles Quint, París, Ellipses, 2006

- Hombres de mala corte. Desobediencias, procesos políticos y gobierno de Indias, segunda mitad del siglo XVI, Madrid, Cátedra, 2017

Schaub, J. F., Les juifs du Roi d'Espagne. Oran, 1507-1669, París, Hachette, 1999

- Le Portugal au temps du comte-duc d'Olivares (1621-1640). Le conflit de juridiction comme exercice politique, Madrid, Casa de Velázquez, 2001

- La France espagnole. Les racines hispaniques de l'absolutisme français, París, Seuil, 2003

Tardieu, J.P., La traite des noirs entre l'océan indien et Montévidéo (Uruguay): fin du XVIIle siècle et début du XIXe, París, L'Harmattan, 2010

Thibaud, Cl., Libérer le Nouveau Monde. La fondation des premières républiques du monde hispanique (Colombie et Vénézuela, 1780-1820), Mordelles, Les Perséides, 2017

Vidal, L., Mazagão, la ville qui traverse l'Atlantique. Du Maroc à l'Amazonie (1769-1783), París, Aubier, 2005

Vincent-Cassy, C., Les saintes vierges et martyres dans l'Espagne du XVIIle siècle. Culte et image, Madrid, Casa de Velázquez, 2011 